\title{
A Case of Pulmonary Alveolar Proteinosis Undergoing Whole Lung Lavage in Combination with Extracorporeal Membrane Oxygenation
}

\author{
Aybuke Kekecoglu ${ }^{1}$, Cengiz Ozdemir ${ }^{2}$, Levent Karasulu², Orcun Unal ${ }^{3}$, Zeynep Nilgun Ulukol ${ }^{4}$, Dilek Bakan N², Fadime Kelesoglu ${ }^{1}$ Burcu \\ Arpinar Yigitbas ${ }^{1 *}$ and Filiz Kosar $\mathbf{A}^{1}$ \\ ${ }^{1}$ Department of Respiratory Intensive Care Unit, Yedikule Chest Disease and Surgery, Training and Research Hospital, Istanbul, Turkey \\ ${ }^{2}$ Department of Chest Disease ,Yedikule Chest Disease and Surgery Training and Research Hospital, Istanbul, Turkey \\ ${ }^{3}$ Department of Cardiovascular Surgery, Istanbul University, Istanbul Medical Faculty, Istanbul, Turkey \\ ${ }^{4}$ Department of Anesthesia and Reanimation, Istanbul University, Istanbul Medical Faculty, Istanbul, Turkey
}

\section{Introduction}

Pulmonary alveolar proteinosis (PAP) is a rare disease whose etiology is not completely known and is characterized by deposition of surfactant proteins and phospholipid-rich acid Schiff (PAS) $(+)$ material in alveoli and bronchioles [1]. One third of the patients die because of progressive hypoxemia and secondary infections while a small proportion does not respond to treatment and subsequently fibrosis develops. In this report, a case of pulmonary alveolar proteinosis admitted to intensive care unit due to progressive hypoxemia and treated with bilateral TLL along with veno-arterial $(\mathrm{v}-\mathrm{a})$ extracorporeal membrane oxygenation (ECMO) is presented.

\section{Case Report}

A 33-year-old male patient was referred to our hospital with the complaints of coughing, shortness of breath and respiratory distress and admitted to intensive care unit. On physical examination, respiration rate was $45 /$ minute. With the delivery of oxygen at a rate of 12 liter per minute, oxygen saturation, arterial blood pressure and apex beat were maintained at $74 \%, 130 / 86 \mathrm{~mm} / \mathrm{Hg}$ and $95 / \mathrm{min}$, respectively. End-inspiratory rales were heard over all zones bilaterally. All other system examinations were normal. Laboratory parameters were as follows: $\mathrm{Hb}: 18.8 \mathrm{~g} / \mathrm{dl}, \mathrm{Htc}: 56.8 \%$, WBC: $12.500 / \mathrm{mm}^{3}$, aspartate aminotransferase (AST): $62 \mathrm{U} / \mathrm{L}$, alanine aminotransferase (ALT): $55 \mathrm{U} / \mathrm{L}$, lactate dehidrogenase (LDH): $808 \mathrm{U} / \mathrm{L}$. Arterial blood gas measurements were as follows in ambient air. $\mathrm{Ph}: 7.33, \mathrm{PaO}_{2}: 57 \mathrm{~mm} /$ $\mathrm{Hg}, \mathrm{PaCO}_{2}: 55,3 \mathrm{~mm} / \mathrm{Hg}$ (Table 1). Other parameters were within normal ranges. He was not a smoker. Patient was hospitalized for six weeks in another respiratory diseases clinic before being referred to our center. It was learnt that dyspnea with exertion, which was present for the last three years, deteriorated within the last three months. On chest $\mathrm{X}$-ray, bilateral widespread alveolar infiltrations, ground glass, and crazy paving appearance were detected (Figures 1 and 2).

Patient was admitted to intensive care unit and initially received non-invasive mechanical ventilation support (NIMV). $\mathrm{FIO}_{2} 70 \%$ was administered in pressure support mode with IPAP $12 \mathrm{mmHg}$ and EPAP $8 \mathrm{mmHg}$. No microbial growth was found in blood, urine and sputum cultures. Sputum cultures were negative for acid-fast bacteria (AFB) and HIV. It was planned to carry out diagnostic bronchoalveolar lavage fluid (BAL) analysis. In spite of constant NIMV support, respiratory distress increased and the patient was intubated under intravenous general anesthesia and fiberoptic bronchoscopic (FOB) examinations were carried out. Bronchoalveolar lavage fluid was obtained from middle lobe of the right lung. Material obtained had the consistency of white milk. During the procedure, oxygen saturation values were between $50-70 \%$ in spite of maximum oxygen support. Procedure was rapidly terminated and the patient was transferred to intensive care unit where he was intubated and put on mechanical ventilator support. In volume control mode, tidal volume was: $500 \mathrm{ml}$ and PEEP: $10 \mathrm{~cm} \mathrm{H}_{2} \mathrm{O}$ and he was supported with , $100 \% \mathrm{FIO}_{2}$ Arterial blood gas measurements were as follows: $\mathrm{pH}: 7.3, \mathrm{PaO}_{2}: 68 \mathrm{~mm} / \mathrm{Hg}, \mathrm{PaCO}_{2}: 53.9 \mathrm{~mm} / \mathrm{Hg}$ and arterial oxygen saturation, $91 \%$. In the pathological examination of $\mathrm{BAL}$, PAS
(+) alveolar proteinosis was detected. Diagnosis of pulmonary alveolar proteinosis was definitively established and in view of the present clinical status, it was decided to carry out total bronchoalveolar lavage of the right lung first in combination with ECMO. Our patient was thought to have primary PAP, he had no malignancy in the past, had no exposure to noxious inhalation materials. Electron microscopy was not performed.

Patients underwent cannulation through the left (19 Fr) and the right $(21 \mathrm{Fr}$ ) femoral arteries. He was $170 \mathrm{~cm}$ tall and weighing $70 \mathrm{~kg}$. Total flow was calculated as $3.8 \mathrm{~L} / \mathrm{min}$. ECMO was initiated with a flow rate of $2.1 \mathrm{~L} / \mathrm{min}$ and oxygen flow $60 \%$ and continued at $3.8 \mathrm{~L} /$ min and 6200 speed. The patients was intubated with 39 no. Double lumen tube and $35 \mathrm{~L}$ SF solution heated to $36 \mathrm{oC}$ was administered into the right lung for lavage and $34.5 \mathrm{lt}$. of fluid was withdrawn (Figure 3 ). During the procedure, oxygen flow was continued and increased to $90 \mathrm{~L} / \mathrm{min}$. After the procedure, intubated patient was transferred to ICU. At the 10th hour of ICU stay, ECMO flow was gradually reduced and ECMO terminated. Patient was followed with invasive mechanical ventilation support. CRP value increased to $103 \mathrm{mg} / \mathrm{L}$. Meropenem and aminoglycoside treatment was initiated. LDH level was reduced to 331 U/L. Chest X-ray was taken for control (Figure 4). Five days after the procedure, the patient was extubated. NIMV support (12-14 hour/ day) was continued. During the follow up period, AST increased to $132 \mathrm{U} / \mathrm{L}, \mathrm{ALT}$ to $311 \mathrm{U} / \mathrm{L}$ and total bilirubin to $3.5 \mathrm{mg} / \mathrm{L}$ In abdominal ultrasonography, no pathology was detected. There was no growth in sputum cultures. AST value was decreased to $49 \mathrm{U} / \mathrm{L}$, ALT to 113 U/L, total bilirubin to $2.1 \mathrm{mg} / \mathrm{L}$ and CRP value to $26 \mathrm{mg} / \mathrm{l}$. In follow up evaluations, dyspnea decreased, but hypoxemia continued to increase. Patient was supported with intermittent NIMV. During masked oxygen respiration at a rate of $8 \mathrm{~L} / \mathrm{min}$, arterial oxygen saturation was $91 \%$. It was decided to apply lung lavage procedure on the left lung as well and the patient was intubated with double lumen endotracheal tube. A total of 28 liters of SF warmed up to were administered to the left lung and a total of 27.4 liters were withdrawn.

Procedure was finished without any complications after bronchial cleaning. Hence, total lung lavage was carried out at seven-day intervals. The patient was extubated on the same day. His oxygen saturation level increased to 95 percent with delivery of oxygen via mask at a rate of

*Corresponding author: Burcu Arpinar Yigitbas, MD Department of Ches Diseases, Yedikule Chest Disease and Surgery Training and Research Hospital Istanbul, Turkey, Tel: +905336653549; E-mail: drburcuayigitbas@yahoo.com

Received November 27, 2014; Accepted March 30, 2015; Published April 03, 2015

Citation: Kekecoglu A, Ozdemir C, Karasulu L, Unal O (2015) A Case of Pulmonary Alveolar Proteinosis Undergoing Whole Lung Lavage in Combination with Extracorporeal Membrane Oxygenation. J Pulm Respir Med 5: 250. doi:10.4172/2161-105X.1000250

Copyright: (C 2015 Kekecoglu A, et al. This is an open-access article distributed under the terms of the Creative Commons Attribution License, which permits unrestricted use, distribution, and reproduction in any medium, provided the original author and source are credited. 
Citation: Kekecoglu A, Ozdemir C, Karasulu L, Unal O, Ulukol ZN, et al. (2015) A Case of Pulmonary Alveolar Proteinosis Undergoing Whole Lung Lavage in Combination with Extracorporeal Membrane Oxygenation. J Pulm Respir Med 5: 250. doi:10.4172/2161-105X.1000250

Page 2 of 3

\begin{tabular}{|c|c|c|}
\hline & Before & After \\
\hline \multicolumn{3}{|l|}{ Biochemical Analysis } \\
\hline Glucose (mg/dl) & 86 & 100 \\
\hline Creatinin (mg/dl) & 1,1 & 0,5 \\
\hline Total Protein (g/dl) & 6,9 & 5,6 \\
\hline Albumin $(\mathrm{g} / \mathrm{dl})$ & 4,4 & 3,3 \\
\hline $\mathrm{Ca}(\mathrm{mmol} / \mathrm{L})$ & 9,7 & 8,6 \\
\hline $\mathrm{Na}(\mathrm{mmol} / \mathrm{L})$ & 133 & 133 \\
\hline $\mathrm{K}(\mathrm{mmol} / \mathrm{L})$ & 4,1 & 4,1 \\
\hline Total Bilirubine (mg/dl) & 1,2 & 2,1 \\
\hline D Bilirubine (mg/dl) & 0,6 & 1,3 \\
\hline AST (U/L) & 62 & 49 \\
\hline $\mathrm{ALT}(\mathrm{U} / \mathrm{L})$ & 55 & 113 \\
\hline LDH (U/L) & 808 & 498 \\
\hline $\mathrm{CRP}(\mathrm{mg} / \mathrm{L})$ & 1 & 26 \\
\hline WBC $\left(10^{3} / \mathrm{mm}^{3}\right)$ & 12,5 & 8,25 \\
\hline Neu $\left(10^{3} / \mathrm{mm}^{3}\right)$ & 9,47 & 6,86 \\
\hline $\operatorname{RBC}\left(10^{6} / \mathrm{mm}^{3}\right)$ & 6,92 & 3,79 \\
\hline HGB (g/dl) & 18,8 & 11,4 \\
\hline HCT (\%) & 56,8 & 33,7 \\
\hline $\operatorname{PLT}\left(10^{3} / \mathrm{mm}^{3}\right)$ & 183 & 277 \\
\hline \multicolumn{3}{|l|}{ Arterial Blood Gas } \\
\hline $\mathrm{pH}$ & 7,40 & 7,55 \\
\hline $\mathrm{pCO}_{2}$ & 38 & 23,8 \\
\hline $\mathrm{pO}_{2}$ & 32 & 250 \\
\hline $\mathrm{HCO}_{3}$ & 29 & 20,8 \\
\hline $\mathrm{SatO}_{2}$ & 72 & 100 \\
\hline $\mathrm{FiO}_{2}$ & $21 \%$ & $100 \%$ \\
\hline PA-a & 72,2 & 439 \\
\hline
\end{tabular}

Table 1: Extracorporeal membrane oxygenation before and after.

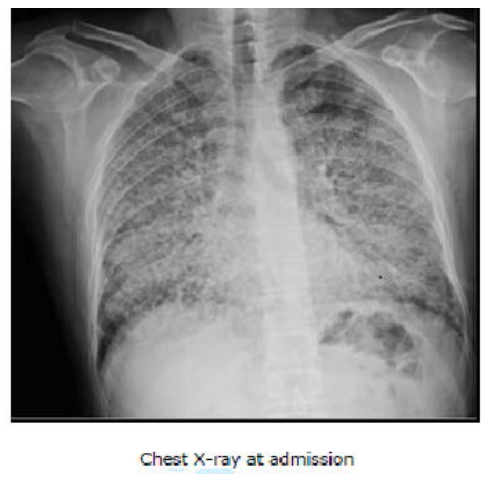

Figure 1: Chest X-ray at admission.

5 liter/7minute. On chest X-ray and thorax CT, marked regression of alveolar infiltrations and fibrotic changes were detected in both lungs (Figure 5). Patient was discharged from the intensive care unit with oxygen support. Due to fibrotic changes and his hypoxemia lung transplantation was recommended.

\section{Discussion}

PAP, which was originally defined by Rosen et al in 1958, is a disorder characterized by the accumulation of surfactant proteins and phospholipid rich PAS(+) materials [1]. It occurs between the ages of 20-50 and its incidence is 2-3 folds higher in males than in females [2]. The most frequent symptom is dyspnea with exertion and dry cough. Pleuritic chest pain, white sticky mucus and hemoptysis may also occur

[3]. Our case was a 33-year-old male presenting with symptoms of dyspnea with exertion, cough and chest pain. Laboratory findings are not specific in PAP. LDH levels are generally high. LDH levels may be decreased with total lung lavage $[4,5]$. $\mathrm{LDH}$ value at presentation was $808 \mathrm{U} / \mathrm{L}$ while it was reduced to $331 \mathrm{U} / \mathrm{L}$ after right lung lavage and to $340 \mathrm{U} / \mathrm{L}$ after left lung lavage.

On chest X-ray of PAP, usually diffuse or patched alveolar infiltrations may be seen. In computerized thorax tomography, especially high resolution CT, in involved lung areas, ground glass appearance, alveolar consolidations and crazy paving appearance produced by the thickening of intralobular and intralobular septa may be observed [6]. On the chest X-ray of our patient, bilateral diffuse alveolar density increase was present. In thorax tomography, areas with ground glass and crazy paving appearance were seen in both lungs. A similar radiological pattern can be seen in pneumonia, hypersensitivity pneumonia, lung edema or contusion and diffuse alveolar hemorrhage syndromes in addition to PAP.

Whole lung lavage is the standard palliative treatment for PAP. The goal is to remove the proteinaceous material deposited in lungs. Lung lavage was first performed by Ramirez Rivera in 1967 for the treatment

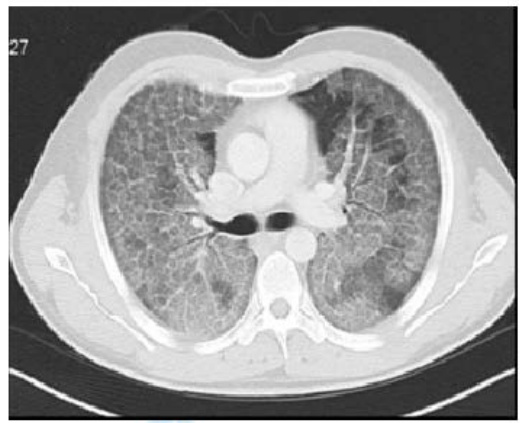

Figure 2: Bilateral ground glass and carzy paving appearance on CT.

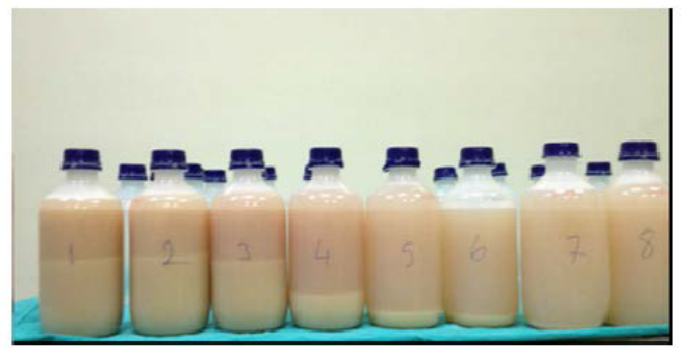

Figure 3: Lavage material of the patient.

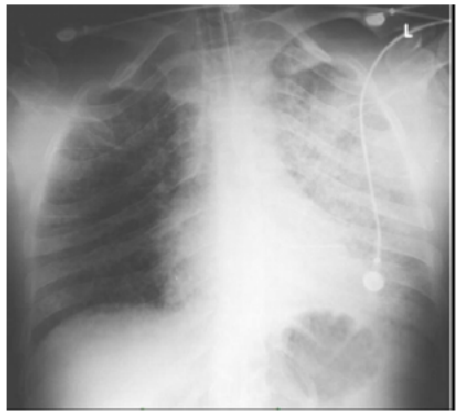

Figure 4: Chest $X$-ray after the lavage of the right lung. 


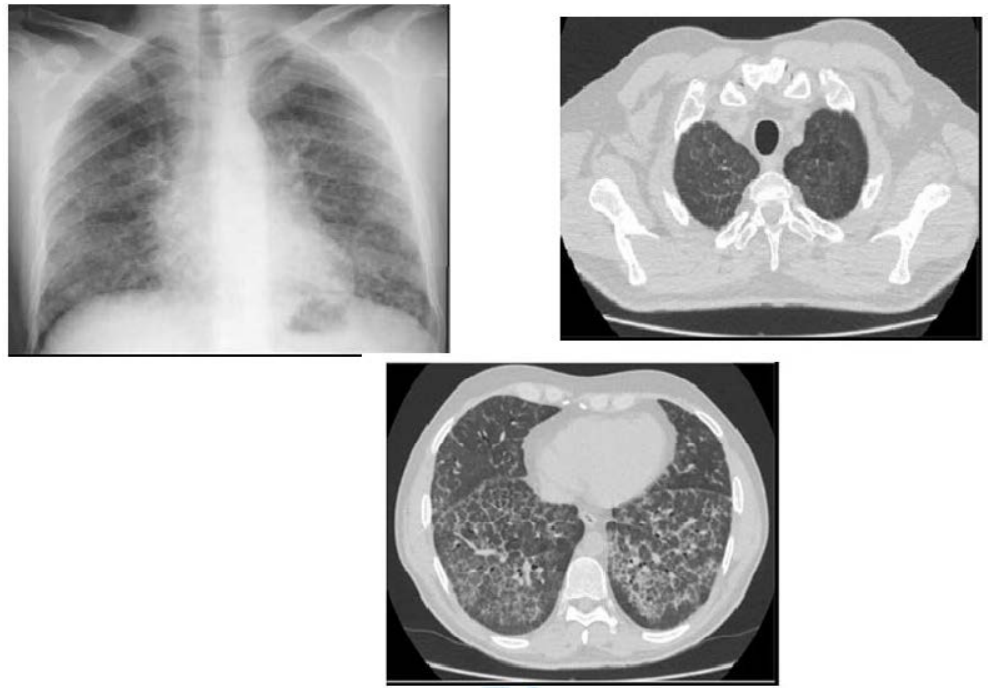

Figure 5: Chest X-ray and thoracal CT sections at discharge.

of PAP [7]. At present, lavage is carried out under general anesthesia, performing single lung ventilation by double lumen endotracheal tube and using SF up to 40 liters. During the procedure, physiological evaluation of cardiovascular and respiratory systems is very important. TLL may lead to hypoxemia due to transient hypoxemia it produces. This risk is highest during lavage, as in this procedure pulmonary blood circulation is directed towards unventilated lung fields. Therefore, the mortality of TLL is reported to be $30 \%$. In addition, there are risks of complications such as pneumothorax, hydrothorax, hemodynamic instability, infection and arrhythmia. In patients with severe hypoxemia, although segment lavage may be performed with fiberoptic bronchoscopy, its benefit is limited. Recently, in patients with severe hypoxemia, whole lung lavage attempts are reported in combination with extracorporeal membrane oxygenation. In this procedure, arteriovenous or veno-venous methods may be used. Arterio-venous route is used more commonly. As weaning is more rapid in this method following procedure, but cannulation is easier in veno-venous method [8-12].

In our case, there was marked refractory hypoxemia. Our case received continuous NIMV support which was supplemented with a $70 \% \mathrm{FIO}_{2}$ and when weaned from oxygen, saturation values fell to $65 \%$ with the development of cyanosis. Diagnostic fiberoptic bronchoscopy could be carried out only under general anesthesia with intubation and during the procedure, saturation values were established to be between $50-70 \%$ in spite of $100 \%$ oxygen support. Therefore, whole lung lavage was performed for the right lung with more marked involvement along with ECMO. Following the procedure, the patient was transferred to ICU intubated. He was weaned from ECMO after 10 hours and extubated five days later. During follow- up evaluations, dyspnea was found to decrease. With 8 liter masked oxygen support, saturation value was 91 percent. On the 7. day, whole lung lavage was carried out on the left lung as well and then oxygen need of the patients was decreased to $4-5 \mathrm{~L} / \mathrm{min}$. In control thorax tomography, findings of fibrosis were present and the patient was discharged with recommendations for transplantation to be performed.

\section{Conclusion}

Although natural history of PAP is variable, one third of the cases may die due to progressive hypoxemia and intervening secondary infections. In cases with severe hypoxemia which can not be improved despite mechanical ventilation support, whole lung lavage with the accompaniment of ECMO may be lifesaving.

\section{References}

1. Rosen SH, Castleman B, Liebow AA (1958) Pulmonary alveolar proteinosis. N Engl J Med 258: 1123-1142.

2. Trapnell BC, Whitsett JA, Nakata K (2003) Pulmonary alveolar proteinosis. N Engl J Med 349: 2527-2539.

3. Shah PL, Hansell D, Lawson PR, Reid KB, Morgan C (2000) Pulmonary alveolar proteinosis: clinical aspects and current concepts on pathogenesis. Thorax 55: 67-77.

4. Wasserman K, Mason GR (2000) Pulmonary Alvolar Protinosis in Murray JF Nadel JA. Textbook of respiratory Medicine (3rdedn) PhiledelphiaWB. Sanders Company 1789-1801 pathogenesis. Thorax 55: 67-77.

5. Menard KJ (2005) Whole lung lavage in the treatment of pulmonary alveolar proteinosis. J Perianesth Nurs 20: 114-126.

6. Murayama S, Murakami J, Yabuuchi H, Soeda H, Masuda K (1999) "Crazy paving appearance" on high resolution CT in various diseases. J Comput Assist Tomogr 23: 749-752

7. Ramirez J, Schultz RB, Dutton RE (1963) Pulmonary Alveolar Proteinosis: A New Technique and Rationale for Treatment. Arch Intern Med 112: 419-431.

8. Cohen ES, Elpern E, Silver MR (2001) Pulmonary alveolar proteinosis causing severe hypoxemic respiratory failure treated with sequential whole-lung lavage utilizing venovenous extracorporeal membrane oxygenation: a case report and review. Chest 120: 1024-1026.

9. Hasan N, Bagga S, Monteagudo J, Hirose H, Cavarocchi NC, et al (2013) Extracorporeal membrane oxygenation to support whole-lung lavage in pulmonary alveolar proteinosis: salvage of the drowned lungs. Bronchology Interv Pulmonol 20: 41-44.

10. Cai HR, Cui SY, Jin L, Huang YZ, Cao B, et al (2005) Pulmonary alveola proteinosis treated with whole-lung lavage utilizing extracorporeal membrane oxygenation: a case report and review. China Zhonghua Jie $\mathrm{He} \mathrm{He} \mathrm{Hu} \mathrm{Xi} \mathrm{Za}$ Zhi 28: 242-244.

11. Sivitanidis E, Tosson R, Wiebalck A, Laczkovics A (1999) Combination of extracorporeal membrane oxygenation (ECMO) and pulmonary lavage in a patient with pulmonary alveolar proteinosis. European Journal of Cardiothoracic Surgery 15: 370-372.

12. Centella T, Oliva E andrade I, Epeldegui A (2005) Case report - Assisted circulation. The use of a membrane oxygenator with extracorporeal circulation in bronchoalveolar lavage for alveolar proteinosis. Interactive Cardiovascular and Thoracic Surgery 4: 447-449. 